\title{
Photoluminescent properties of fresnoite phosphors prepared from phase-separated $\mathrm{BaO}-\mathrm{TiO}_{2}-\mathrm{SiO}_{2}$ glasses
}

\author{
Hiroyuki HIJIYA, Tetsuo KISHI and Atsuo YASUMORI ${ }^{\dagger}$ \\ Department of Materials Science and Technology, Tokyo University of Science, 2641, Yamazaki, Noda-shi, Chiba, $278-8510$
}

Glass ceramic phosphors containing fresnoite $\left(\mathrm{Ba}_{2} \mathrm{TiSi}_{2} \mathrm{O}_{8}\right)$ were prepared from glasses both within and outside the immiscibility region of the $\mathrm{BaO}_{-} \mathrm{TiO}_{2}-\mathrm{SiO}_{2}$ system by conventional melt-quenching and subsequent heat treatment. The phosphors showed blue-white photoluminescence (PL) under ultraviolet excitation, and the effects of the crystalline phase precipitated and the fine structure of the ceramics on their PL properties were examined. Phase-separated textures were observed in the samples with compositions within the immiscibility region. The predominant crystalline phase precipitated in the heat-treated sample was fresnoite. Sample PL intensity was related not only to the amount of precipitated fresnoite, but also to the microstructure of the sample resulting from phase separation. The highest PL intensity was obtained from a $22 \mathrm{BaO}^{\circ} \cdot 11 \mathrm{TiO}_{2} \cdot 67 \mathrm{SiO}_{2}$ sample from the immiscibility region, because of the formation of an appropriate fine glass-ceramic structure for photoexcitation of fresnoite.

(C)2008 The Ceramic Society of Japan. All rights reserved.

Key-words : Phase separation, Fresnoite, Glass-ceramics

[Received April 28, 2008; Accepted November 20, 2008]

\section{Introduction}

Recently, phosphor materials have gathered increasing attention because they are key materials for light-emitting and display devices such as light-emitting diodes (LEDs), plasma display panels (PDPs), and field emission displays (FEDs). In order to enhance the emission intensity and lifetime of these devices, new phosphor materials with high, stable luminescence are desirable. Development of blue phosphors is especially important, because of the limited number of stable blue luminescent materials currently available.

There have been a number of investigations of inorganic phosphors activated with rare-earth or transition-metal ions, and some of these phosphors are already in use. For example, $\mathrm{BaMgAl}_{10} \mathrm{O}_{17}$ : $\mathrm{Eu}^{2+}(\mathrm{BAM})$ is the most widely used blue phosphor, employed in various commercial applications such as fluorescent lights and PDPs, because it has a strong blue emission under ultraviolet (UV) excitation. However, the stability of BAM is insufficient, especially for long-lifetime devices. Its photoluminescent (PL) efficiency decreases during the display manufacturing process, particularly during baking and ion sputtering, and also during device operation due to the UV irradiation. This degradation of PL properties occurs via oxidation of $\mathrm{Eu}^{2+}$ ions ${ }^{1)}$ and/or a change in the local structure of the BAM host around Eu ions. ${ }^{2)}$

Fresnoite $\left(\mathrm{Ba}_{2} \mathrm{TiSi}_{2} \mathrm{O}_{8}\right)$ is a natural silicate mineral, well known to exhibit blue-white luminescence with no activator. ${ }^{3)}$ Fresnoite is a stable crystalline phase, ${ }^{4}$ and is easily synthesized by a conventional solid-state reaction in air. ${ }^{5), 6)}$ Its crystal structure is tetragonal. ${ }^{7)}$ The luminescent center of fresnoite is thought to be based on a $\mathrm{TiO}_{5}{ }^{6-}$ structure and that of $\mathrm{BaTiSi}_{3} \mathrm{O}_{9}$ (benitoite), a related crystal, is based on a $\mathrm{TiO}_{6}{ }^{8-}$ structure. ${ }^{8), 9)}$ Fresnoite phosphor is expected to have a higher thermal stability,

Corresponding author: A. Yasumori; E-mail: yasumori@rs.noda. tus.ac.jp compared with $\mathrm{Eu}^{2+}$-doped phosphors such as BAM, which are unstable at high temperatures in air. Also, because fresnoite can be prepared from conventional raw materials, low production costs may be possible.

Crystallization and phase separation are both well-known phenomena in melt-quenched glasses. In general, crystallization of a melt-quenched glass proceeds by nucleation and growth mechanisms. Crystallization of the glass is likely to occur at the surface of the glass because the surface acts as a heterogeneous nucleation site. Therefore, practical crystallized glasses (glass ceramics such as tableware and building materials) are prepared by adding a nucleation agent, such as $\mathrm{Al}_{2} \mathrm{O}_{3}, \mathrm{TiO}_{2}$ or $\mathrm{ZrO}_{2}$, in order to obtain bulk (homogeneous) crystallized glass. Takahashi et al. reported that a crystallized glass with stoichiometric fresnoite composition was prepared by glass-crystallization of a $\mathrm{BaO}-\mathrm{TiO}_{2}-\mathrm{SiO}_{2}$ system, and the glass showed blue-white luminescence and second-harmonic generation. ${ }^{10)}$ They also obtained fresnoite crystal structures by surface crystallization of $\mathrm{BaO}-\mathrm{TiO}_{2}-\mathrm{SiO}_{2}, \mathrm{BaO}-\mathrm{TiO}_{2}-\mathrm{GeO}_{2}$ and $\mathrm{SrO}-\mathrm{TiO}_{2}-\mathrm{SiO}_{2}$ systems, and observed high second-harmonic generation from the $\mathrm{BaO}-\mathrm{TiO}_{2}-\mathrm{GeO}_{2}$ sample. ${ }^{11)}$

On the other hand, phase separation can also be applied to the preparation of commercial functional glass materials, such as high chemical and thermal durability glassware or porous, high surface area materials with a nanometer- to micrometer-scale phase-separated structure. In glass crystallization, the boundary of two glass phases in a fine phase-separated structure can act as a heterogeneous nucleation site, resulting in bulk crystallization of the glasses.

In phosphor materials, it is very important to optimize the morphology of the phosphor in order to obtain high luminous intensity, since a fraction of incident UV light is reflected or scattered on the surface, and only the remaining light penetrates the phosphor to generate luminescence. ${ }^{12)}$ Therefore, the phase separation and subsequent crystallization is a suitable method for the preparation of a phosphor with appropriate microstructure for 
improved PL properties. Furthermore, a transparent glass matrix surrounding the precipitated phosphors can protect them from reduction, oxidation, or absorption of de-activators, such as various organic substances. We have already reported several studies of the PL properties of phase-separated glasses in silicate systems such as $\mathrm{Y}_{2} \mathrm{O}_{3}-\mathrm{Al}_{2} \mathrm{O}_{3}-\mathrm{SiO}_{2}$ : $\mathrm{Eu},{ }^{13)} \mathrm{CaO}-\mathrm{Al}_{2} \mathrm{O}_{3}-\mathrm{SiO}_{2}$ : $\mathrm{Eu},{ }^{14)}$ and $\mathrm{ZnO}-\mathrm{SiO}_{2}: \mathrm{Mn}^{2+} .{ }^{15}$

In this study, we prepared a fresnoite phosphor from a glass in the $\mathrm{BaO}-\mathrm{TiO}_{2}-\mathrm{SiO}_{2}$ ternary system, which has an immiscibility region, using a glass-crystallization method. The effects of the crystalline phase and the phase-separation texture on PL properties were examined.

\section{Experimental}

The glass compositions prepared were $(40-2 x / 3) \mathrm{BaO}-(20-x /$ 3) $\mathrm{TiO}_{2}-(40+x) \mathrm{SiO}_{2}$ mol\% ( $\left.x=0-39\right)$, in which $x=0$ corresponds to the composition of fresnoite $\left(\mathrm{Ba}_{2} \mathrm{TiSi}_{2} \mathrm{O}_{8}\right)$. Figure 1 shows a schematic illustration of the phase diagram of $\mathrm{BaO}-\mathrm{TiO}_{2}-\mathrm{SiO}_{2}$ ternary system and the compositions prepared in this study. The shaded area in Fig. 1 shows the reported glass-forming area of this system, ${ }^{16)}$ and the quadrilateral area represents the immiscibility region expected from the stable immiscibility region of the $\mathrm{BaO}-\mathrm{SiO}_{2}$ system at $1200^{\circ} \mathrm{C}^{17)}$ and the metastable one of the $\mathrm{TiO}_{2}-\mathrm{SiO}_{2}$ system at $1700^{\circ} \mathrm{C} .^{18)}$ Reagent-grade raw materials: $\mathrm{BaCO}_{3}$ (High Purity Chemicals, 99.5\%), $\mathrm{TiO}_{2}$ (Wako Pure Chem. Ind., Ltd., 98.5\%), and $\mathrm{SiO}_{2}$ gel (Wako Pure. Chem. Ind., Ltd.) were weighed and mixed in a mortar. The glass batch was melted in an alumina crucible at $1500-1650^{\circ} \mathrm{C}$ depending on the glass composition. After $1 \mathrm{~h}$, the glass melt was quenched on a brass plate to obtain the glass.

The phase-separation textures of the melt-quenched glass samples were observed by scanning electron microscope (SEM; JEOL, JSM-5800) after the samples were cut and polished to a mirror surface, but not chemically etched. Thermal analysis was performed on the melt-quenched glasses using differential thermal analysis (DTA; Shimadzu Corp., DTA-50) in air to find the crystallization temperature, and to determine the heat-treatment temperatures for crystallization. The particle size of the ground sample glasses for DTA measurements was 32-45 $\mu \mathrm{m}$, and the heating rate was $10 \mathrm{~K} / \mathrm{min}$. The melt-quenched glasses

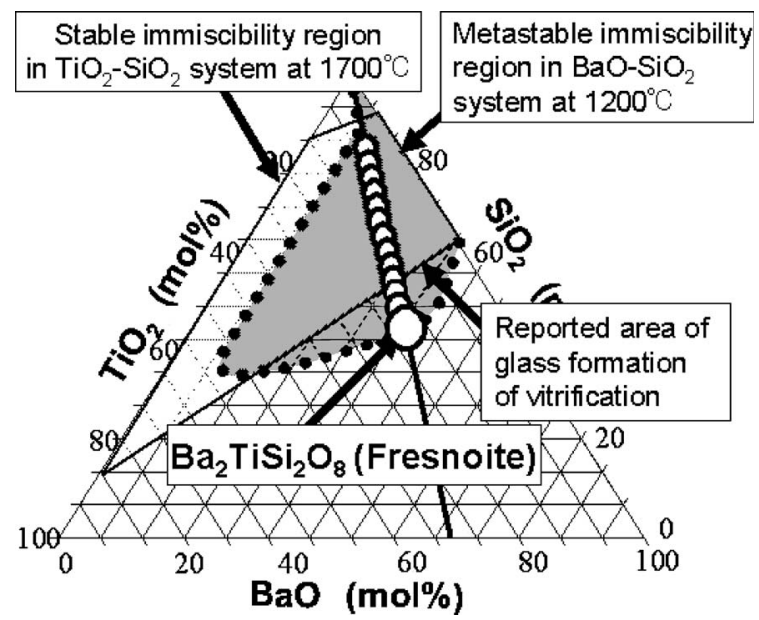

Fig. 1. Chemical compositions of samples in the phase diagram of $\mathrm{BaO}-\mathrm{TiO}_{2}-\mathrm{SiO}_{2}$ ternary system. The shaded area is the glass-forming region, ${ }^{16)}$ and the quadrilateral area is the immiscibility region expected, based on the immiscibility region of $\mathrm{BaO}-\mathrm{TiO}_{2}{ }^{17)}$ and $\mathrm{TiO}_{2}-\mathrm{SiO}_{2}$ systems. ${ }^{18)}$ were heat-treated in air for $24 \mathrm{~h}$ at $800-1200^{\circ} \mathrm{C}$ to obtain the glass-ceramics (crystallized samples). The crystalline phase precipitated in the sample was examined by X-ray diffraction (XRD; Shimadzu Corp., XRD-6100) at room temperature. The PL spectra were measured on the sample powders using a fluorescence spectrophotometer (Shimadzu Corp., RF-5000). The excitation wavelength was $254 \mathrm{~nm}$ for all samples. For the PL measurements, the sample holder (diameter: $15 \mathrm{~mm}$; depth: $1 \mathrm{~mm}$ ) was filled with powdered sample, then the front of the holder was covered with a silica glass plate. 200-mesh passed samples were used for the XRD and PL measurements.

\section{Results and discussion}

In the melt-quenched samples with $x=21-39$, devitrification was observed by the naked eye. Figure 2 shows SEM images of the melt-quenched samples with $x=21-39$, which exhibited phase-separated texture. Outside the above composition range, the phase-separated texture could not be observed by SEM. In Fig. 2, the dark and bright areas correspond to a $\mathrm{SiO}_{2}$ rich phase and a $\mathrm{BaO}-\mathrm{TiO}_{2}$ rich phase, respectively. Figures $2(\mathrm{a}-1)$ and $(\mathrm{a}-2)$ show the cross-sectional and surface SEM images of the $x=21$ glass, respectively. The interior of $x=21$ glass showed no phase-separation texture, whereas the surface of the same sample exhibits phase separation caused by nucleation and growth decomposition. The samples with compositions of $x=24-36$ (Figs. 2(b)-(f)) consisted of a $\mathrm{BaO}-\mathrm{TiO}_{2}$ rich matrix surrounding $\mathrm{SiO}_{2}$-rich particles with diameters of about 200-700 nm. Depending on the observa-
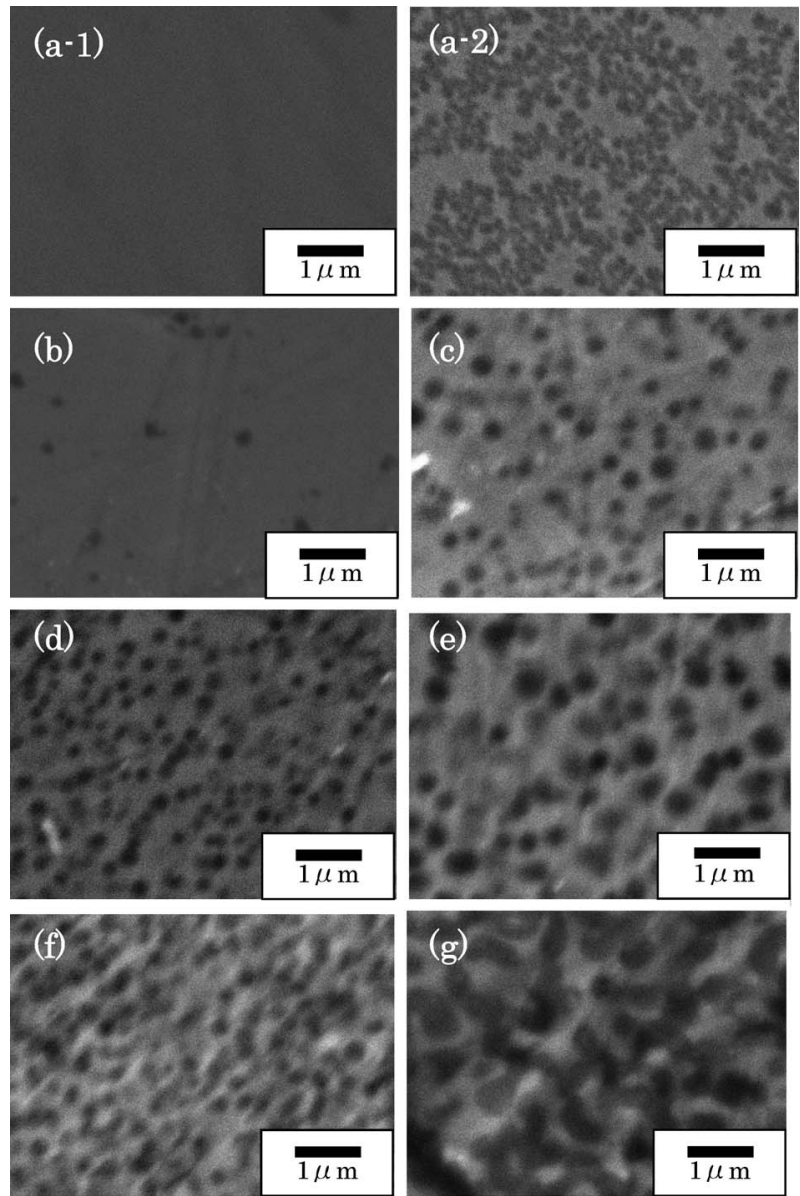

Fig. 2. SEM images of melt-quenched samples: (a-1) $x=21$, (a-2) $x=$ 21, (b) $x=24$, (c) $x=27$, (d) $x=30$, (e) $x=33$, (f) $x=36$, and (g) $x=39$. 
tion region of the sample, the $\mathrm{SiO}_{2}$-rich phase showed variations in particle size. However, the area ratio of $\mathrm{SiO}_{2}$-rich phase to $\mathrm{BaO}-\mathrm{TiO}_{2}$-rich phase was independent of observation region, and increased with increasing amount of $\mathrm{SiO}_{2}$. The microstructure of the sample with $x=39$ shown in Fig. 2(g) exhibits an interconnected texture caused by spinodal decomposition.

It is necessary to know the characteristic temperatures of the melt-quenched samples in order to determine the appropriate heat-treatment temperature for crystallization of the meltquenched glass into fresnoite. Figure 3 shows examples of the obtained DTA curves for samples with $x=0,9$, and 27. The exothermic peaks on the curves are due to crystallization. On the curve from the sample with $x=0$, indistinct exothermic peaks around 860,910 , and $955^{\circ} \mathrm{C}$ were observed. On the contrary, distinct exothermic peaks were observed at 900 and $930^{\circ} \mathrm{C}$ in samples with $x=9$ and 27 , respectively. Thus, we heat-treated the melt-quenched samples for crystallization above the peak temperatures observed in the DTA curves, mainly at $1200^{\circ} \mathrm{C}$.

Figure 4 shows the XRD patterns of melt-quenched and heattreated samples with $x=9$. The heat treatment temperatures were 800,900 , and $1200^{\circ} \mathrm{C}$, and the holding time was $24 \mathrm{~h}$. All heattreated samples showed the diffraction peaks of fresnoite on their patterns. The amount of precipitated fresnoite increased when the heat-treatment temperature rose. Therefore, melt-quenched

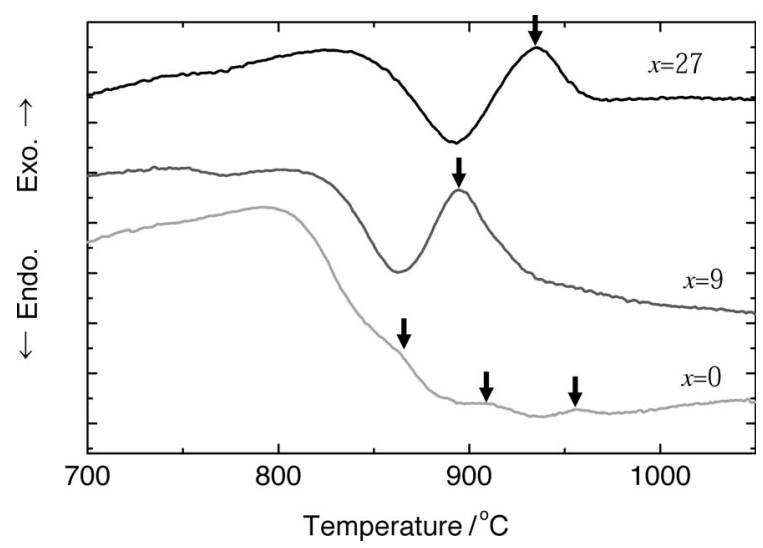

Fig. 3. DTA curves of melt-quenched samples with $x=0,9$, and 27 .

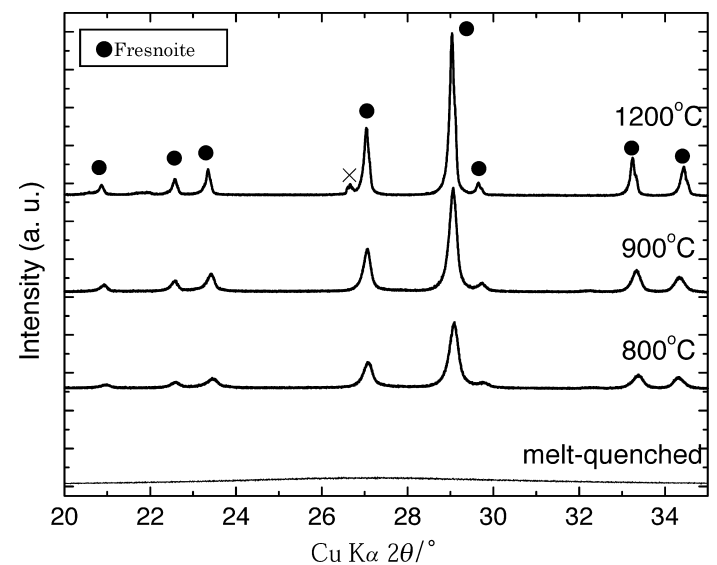

Fig. 4. XRD patterns of the melt-quenched samples and glass ceramic samples with $x=9$, heat-treated at 800,900 , and $1200^{\circ} \mathrm{C} . \times$ is the unidentified peak. glasses of other compositions were also heat-treated at $1200^{\circ} \mathrm{C}$, to increase the amount of fresnoite. Figure 5 shows the XRD patterns of heat-treated samples with $x=0,9$ and 27 at $1200^{\circ} \mathrm{C}$ for $24 \mathrm{~h}$. Though the diffraction peaks due to fresnoite were found in the XRD patterns for all compositions, the peaks due to cristobalite $\left(\mathrm{SiO}_{2}\right)$ were also observed in $x=27$. The other peaks marked as " $x$ " in Figs. 4 and 5 have not been identified. The integrated XRD intensities of the fresnoite (211) diffraction peak at $29.0^{\circ}$ of glass ceramics obtained after heat treatment at $1200^{\circ} \mathrm{C}$ for $24 \mathrm{~h}$ was selected to evaluate the amount of precipitated fresnoite phase. These integrated intensities are plotted against the concentration of $\mathrm{SiO}_{2}, x \mathrm{~mol} \%$, in Fig. 6. The shaded zone in the figure indicates the composition where phase-separated texture was observed by SEM in the melt-quenched samples. The amount of fresnoite phase increased gradually with increasing $x$, and showed little change in the range from $x=9$ to 33. Above $x$ $=33$, the amount of fresnoite phase decreased.

Figure 7 shows the PL spectra of glass-ceramics with compositions of $x=0,9$, and 27 , heat treated at $1200^{\circ} \mathrm{C}$ for $24 \mathrm{~h}$. A broad PL peak at $467 \mathrm{~nm}$ was observed for all samples. These PL spectra are similar in peak wavelength and spectral range to those reported by Blasse et al. ${ }^{3)}$ However, the PL intensity changed, depending on glass composition, although their peak wavelength and the shape of the spectrum were nearly identical. This indicates that PL from the glass ceramic samples was caused by the same luminescence center. Figure 8 shows the

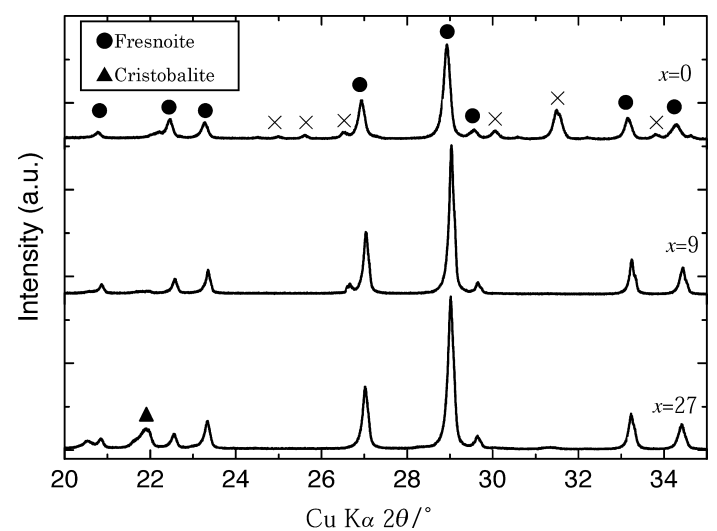

Fig. 5. XRD patterns of glass ceramics with $x=0,9$, and $27 . \times$ is the unidentified peak.

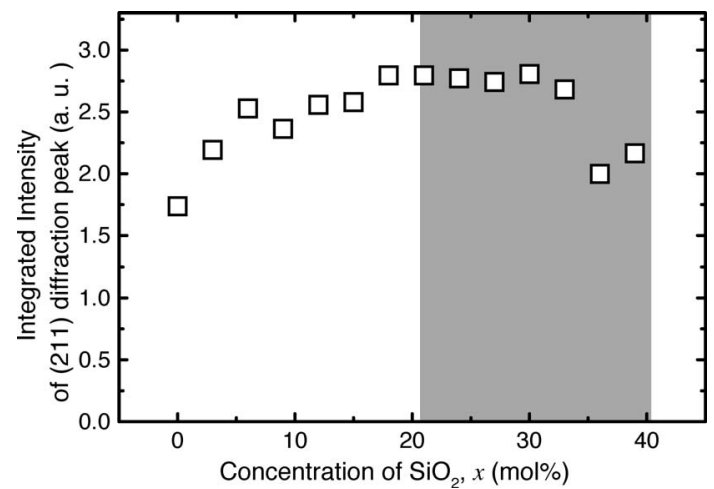

Fig. 6. Change in the integrated intensity of the (211) diffraction peak of fresnoite versus the concentration of $\mathrm{SiO}_{2}$ in the glass ceramics. The shaded zone indicates the immiscibility range of the system. 


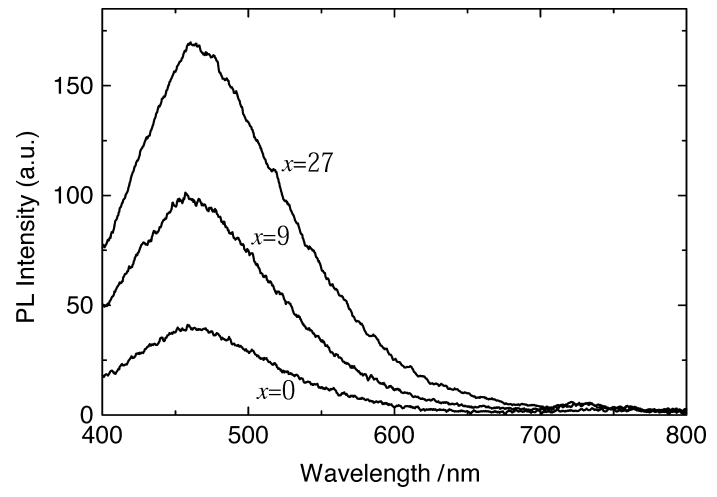

Fig. 7. PL spectra of glass ceramics with $x=0,9$, and 27, excited at $254 \mathrm{~nm}$.

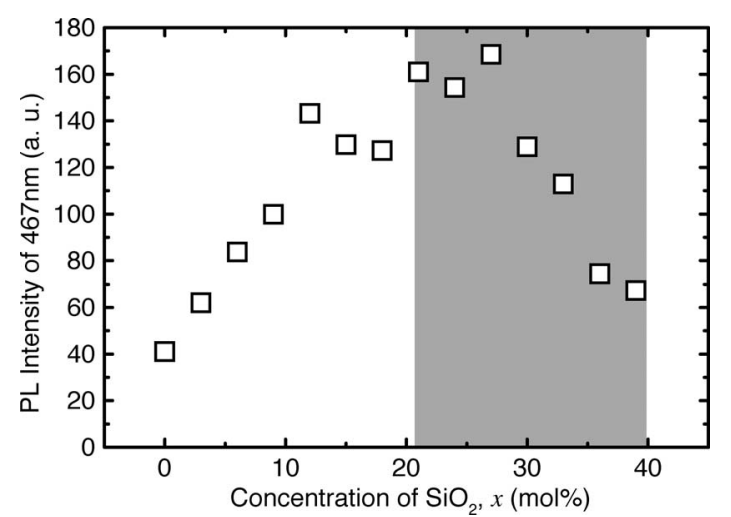

Fig. 8. Change in PL intensity of glass ceramics at $467 \mathrm{~nm}$ versus the concentration of $\mathrm{SiO}_{2}$ in the glass ceramics. The shaded zone indicates the immiscibility range of the system.
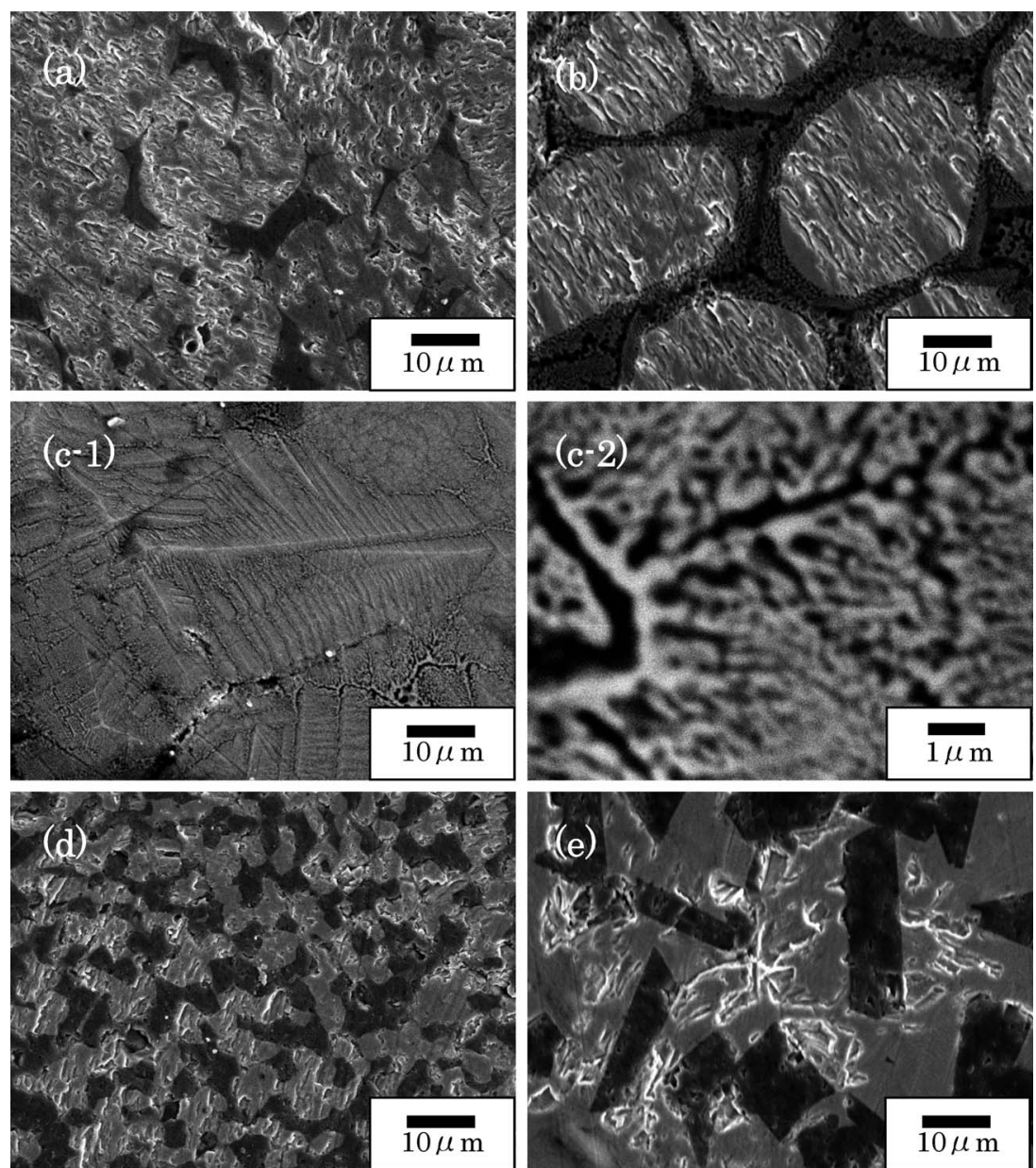

Fig. 9. SEM images of glass ceramics: (a) $x=9$, (b) $x=15$, (c-1) $x=21$, (c-2) $x=21$, (d) $x=27$, and (e) $x=30$.

change of PL intensity at the wavelength of $467 \mathrm{~nm}$ versus the concentration of $\mathrm{SiO}_{2}, x \mathrm{~mol} \%$. In the series of samples with $x<$ 21 , which had no phase-separation texture, the PL intensity increased with increasing $x$ up to $x=12$, and become almost constant. In the composition range of $21 \leq x \leq 39$, where the melt-quenched samples had phase-separated textures, the PL intensities of samples with $x=21-27$ were higher than for $x=$ $12-18$, the highest of the samples lacking phase separation, and decreased steeply for samples with higher $\mathrm{SiO}_{2}$ concentrations. We can explain the increase and decrease of PL intensity in the composition range of $0 \leq x \leq 6$ and $33 \leq x \leq 39$ from the change in the amount of precipitated fresnoite shown in Fig. 6. On the other hand, the composition-dependence of PL intensity for samples with $9 \leq x \leq 30$ cannot be explained in this way, since the amount of fresnoite did not change over this composition range.

The internal structure of phosphor materials is one of the most 
important factors in highly-PL materials. Therefore, we observed the morphology of the fresnoite phosphor crystals in the samples by SEM in order to reveal the origin of the improvement in PL for samples with $x=21-27$. Figure 9 shows cross-sectional SEM images of samples with (a) $x=9$, (b) $x=15$, (c-1) $x=21$, (d) $x$ $=27$, and (e) $x=30$, heat treated at $1200^{\circ} \mathrm{C}$ for $24 \mathrm{~h}$. Figure $9(\mathrm{c}-$ 2 ) is a magnified view of Fig. 9(c-1). The samples with $x=9$ and 15 consisted of fresnoite crystals with a size greater than several tens of micrometers, and a lesser $\mathrm{SiO}_{2}$-rich phase (dark area). On the other hand, the samples with $x=21$ and 27 had a submicrostructure and microstructure, respectively. These consisted of fine fresnoite crystals (or $\mathrm{BaO}-\mathrm{TiO}_{2}$-rich phase) and a $\mathrm{SiO}_{2}$-rich glass phase, in nearly equal proportion. As Fig. 9(e) shows, the $x=30$ glass ceramics consists of a continuous fresnoite phase (or $\mathrm{BaO}-\mathrm{TiO}_{2}$-rich phase) and a polygonal grained cristobalite structure. The structures of the phosphors with compositions of $x=$ 21 and 27 are very effective at decreasing the surface reflectivity of the glass ceramics, increasing the fraction of excitation light transmitted into the phosphor. ${ }^{19)}$ This allows the penetration of incident UV light into the glass ceramics and subsequent internal scattering. These phenomena, which were induced by the particular fine structure arising from phase separation, resulted in an improvement of PL because the incident UV light was efficiently absorbed by the fresnoite crystals. These results demonstrate that bulk crystallization of the glass, caused by heterogeneous nucleation at the boundary of two glassy phases, and the resulting microstructure, which consisted of fine fresnoite and $\mathrm{SiO}_{2}$-rich glassy phases, were very effective at enhancing the PL intensity.

\section{Conclusion}

The photoluminescent properties of glass ceramics in the $\mathrm{BaO}-\mathrm{TiO}_{2}-\mathrm{SiO}_{2}$ system were investigated. The samples exhibited blue-white luminescence due to the precipitation of fresnoite crystals, and the PL intensity depended on both the amount of precipitated fresnoite and the microstructure formed in the sample due to phase separation. The sample obtained from a composition region leading to phase-separation showed the highest PL intensity, because of an internal structure consisting of fine fresnoite crystals and $\mathrm{SiO}_{2}$-rich glassy phase. The results indicate that the crystallization of phase-separated glasses provides the potential to prepare highly luminescent, stable phos- phor materials.

\section{References}

1) S. Ochi, T. Matsuoka, S. Tanaka and H. Kobayashi, J. Electrochem. Soc., 145, 3903-3907 (1998).

2) K.-S. Sohn, S. S. Kim and H. D. Park, Appl. Phys. Lett., 81, 1759-1761 (2002).

3) G. Blasse, J. Inorg. Nucl. Chem., 30, 2283-2284 (1968).

4) Von N. Koppen and A. Dietzel, Glastech. Ber., 49, 199-206 (1976).

5) N. Funabashi, K. Nishio and A. Yasumori, Annual Meeting of The Ceramic Society of Japan, 2K06, p.285 (2004).

6) H. Hijiya, N. Kiso, K. Soga, K. Nishio and A. Yasumori, Annual Meeting of The Ceramic Society of Japan, 3F09, p.230 (2005).

7) J. T. Alfors, M. C. Stinson and R. A. Matthews, Am. Mineral, 50, 314-340 (1965).

8) "Luminescence and Energy Transfer, with Contributions" by G. Blasse, K. C. Bleijenberg and R. C. Powell, Springer, Berlin (1980) pp. 17-23.

9) M. Gaft, L. Nagli, G. Waychunas and D. Weiss, Phys. Chem. Minerals, 31, 365-373 (2004).

10) Y. Takahashi, K. Kitamura, S. Inoue, Y. Benino, T. Fujiwara and T. Komatsu, J. Ceram. Soc. Japan, 113, 419-423 (2005).

11) Y. Takahashi, Y. Benino, T. Fujiwara and T. Komatsu, J. Applied Physics, 95, 3503-3508 (2004).

12) Y.-S. Fran and T.-Y. Tseng, J. Phys. D: Appl. Phys., 32, 513-517 (1999).

13) N. Kiso and A. Yasumori, in Proc. XX ICG, O-07-070 (2004).

14) T. Ohgaki, A. Higashida, K. Soga and A. Yasumori, J. Electro. Soc., 154, J163-J166 (2007).

15) T. Ohgaki, Y. Nagumo, K. Soga and A. Yasumori, J. Ceram. Soc. Japan, 115, 201-204 (2007).

16) "Garasu Kougaku Handbook (Handbook of Glass Engineering, in Japanese)," Ed. by M. Yamane, I. Yasui, M. Wada, Y. Kokubu, R. Terai, K. Kondou and S. Ohgawa, AsakuraShoten, Tokyo (1999) p.672.

17) T. P. Seward and D. R. Uhlmann, J. Am. Ceram. Soc., 51, 634-643 (1968).

18) R. C. DeVries, R. Roy and E. F. Osborn, Trans. J. Br. Ceram. Soc., 59, 520-540 (1954).

19) I. Y. Jung, Y. Cho, S. G. Lee, S. H. Sohn, D. K. Kim, D. K. Lee and Y. M. Kweon, Appl. Phys. Lett., 87, 191908 (2005). 